\title{
Distraction index measurement on the dog's hip joint using a dedicated software
}

[Medição do índice de distração da anca do cão usando um software especial]

\author{
S. Alves-Pimenta ${ }^{1,2}$, A. Santana ${ }^{1,3}$, J. Martins ${ }^{1,3}$, B. Colaço $^{1,2}$, L. Gonçalves ${ }^{2,4}$, M. Ginja ${ }^{* 1,2}$ \\ ${ }^{1}$ CITAB - University of Trás-os-Montes and Alto Douro - Vila Real, Portugal \\ ${ }^{2}$ University of Trás-os-Montes and Alto Douro - Vila Real, Portugal \\ ${ }^{3}$ Faculty of Veterinary Medicine - Lusófona University - Lisbon, Portugal \\ ${ }^{4}$ Institute for Systems and Computer Engineering, Technology and Science - Porto, Portugal
}

\begin{abstract}
The aim of this study was to test the accuracy of a new automated computer software tool for the assessment of passive hip laxity. The hip laxity was estimated using the dedicated computer software by two blinded evaluators, one previously trained and one without specific training for distraction index measurement, in two independent sessions using 230 hip joints from 115 dogs that underwent screening for passive hip laxity using the distraction view. Previously, all of these radiographs were sent to PennHIP Analysis Center for an official distraction index record. The measurement repeatability of the two sessions was adequate for both evaluators. The reproducibility of the official distraction index measurement, mean distraction index \pm standard deviation $0.44 \pm 0.15$, was adequate $(\mathrm{P}>0.05)$ for the trained evaluator, $0.44 \pm 0.15$, and nonadequate $(\mathrm{P}<0.05)$, for the non-trained evaluator $0.47 \pm 0.17$. The distraction index measurement tool proposed can be used with confidence for hip laxity evaluation by trained evaluators, as it provided good repeatability and reproducibility of official reports. The simplicity of the process described leads to a less time-consuming and more affordable procedure.
\end{abstract}

Keywords: dog, distraction index, hip dysplasia, orthopaedics, osteoarthritis

\section{RESUMO}

O objetivo deste estudo foi testar a viabilidade de uma nova ferramenta de software informático para avaliação da lassitude articular passiva da articulação coxofemoral. A lassitude articular da articulação coxofemoral foi estimada usando-se um programa informático especial, desenvolvido para o efeito, por dois avaliadores, um com treino prévio e outro não treinado, na medição do índice de distração, em duas sessões independentes, utilizando-se 230 articulações coxofemorais de 115 cães, as quais efetuaram o rastreio de displasia coxofemoral realizando a projeção de distração da articulação coxofemoral. Previamente, todas as radiografias foram enviadas para o PennHIP Analysis Center, para se obter uma medida oficial do índice de distração. A repetibilidade das medições das duas sessões foi adequada para ambos os avaliadores. A reprodutibilidade do indice de distração oficial, média \pm desvio-padrão $0,44 \pm 0,15$, foi adequada $(P>0,05)$ para o avaliador treinado, $0,44 \pm 0,15$, e não adequada $(P>0,05)$ para o avaliador não treinado, 0,47士0,17. A ferramenta de medição do índice de distração proposta pode ser usada com segurança na medição do índice de distração por avaliadores treinados, uma vez que mostra uma adequada repetibilidade e reprodutibilidade das medições oficiais do índice de distração. A simplicidade do processo apresentado torna-o menos demorado e mais econômico.

Palavras-chave: cão, índice de distração, displasia coxofemoral, ortopedia, osteoartrite

Recebido em 3 de setembro de 2019

Aceito em 10 de dezembro de 2019

*Autor para correspondência (corresponding author)

E-mail: mginja@utad.pt 


\section{INTRODUCTION}

Hip dysplasia is a hereditary orthopaedic disorder affecting dogs (Gaspar et al., 2016; Martins et al., 2017a). It was first described in 1935, and since then has been the subject of intense investigation (Schnelle, 1935). The manifestation of the disorder is determined by genetic factors, but also influenced by environmental factors, such as age, growth rate and body condition (Ginja et al., 2009a; Zhang et al., 2009; Powers et al., 2010; Wilson et al., 2011). However, despite the various methods of reproductive control, it remains a common condition in large to giant breeds of dogs (Genevois et al., 2008; Ginja et al., 2009b). Dogs affected present a degenerative joint condition due to biomechanical trauma, and sometimes evident clinical signs as pain, decreased activity, or lameness (Ginja et al., 2010; Anderson, 2011).

There is no adequate molecular diagnosis for hip dysplasia (Gaspar et al., 2016) and the screening worldwide requires radiographic examination (Martins et al., 2017b; 2019, in press). Screening is based in the assessment of stablished parameters, taking into account characteristic radiographic degenerative joint signs, observed on the standard ventrodorsal hip-extended view, in dogs over one year of age (Verhoeven et al., 2007; Bausman and Wendelburg, 2010). However, the predisposition to the development of hip dysplasia in adult animals may be assessed in dogs over four months, by hip joint laxity evaluation (Smith et al., 1990). Hip laxity is considered the main risk factor for development of dysplasia (Smith et al., 1990; Farese et al., 1999; Ginja et al., 2008a).

The hip joint laxity is measured in a ventrodorsal distraction hip view, with the joints under stress, performed using a specific hip distractor (Smith et al., 1990; Tôrres et al., 2005; Vezzoni et al., 2005; Taroni et al., 2018). The distractor acts as a fulcrum, promoting the separation between the femoral head and the acetabulum, and then the hip joint laxity is determined calculating the distraction index. This medical information can be helpful for the treatment of animals or for breeding purposes (Smith et al., 1990; Vezzoni et al., 2005). A greater dissemination and use of hip laxity for monitoring dog breeds would be very helpful. Thousands of x-rays are made every year all over the world to evaluate dog`s passive hip laxity (Smith et al., 1990; Vezzoni et al., 2005;
Butler and Gambino, 2017; Taroni et al., 2018). However, a broader knowledge of hip laxity in canine populations in the world is hampered by the existence of only one certificating entity in the world, the PennHIP Antech Imaging Services in United States charging the respective reading fees and centralizing all the technical information.

At the beginning, the distraction index was calculated in hard radiographs using the best fitting circle drawn in a transparent acetate placed over femoral head and acetabulum and its centers were manually marked. Nowadays, with the digital development of radiographic images, a general imaging measurement computer software can be used for this purpose, with similar technical steps (Ginja et al., 2006).

The purpose of the present study was to evaluate the accuracy of a specific dedicated semiautomatic computer software that was developed to simplify the process of measuring the distraction index to make it less time consuming, by comparing its results with the official PennHIP Analysis Center reports.

\section{MATERIALS AND METHODS}

This was a retrospective study based on the analyses of 230 hips of $115 \mathrm{dogs}$ (50 males and 65 females), 107 Estrela Mountain dogs and 8 Portuguese Water dog that underwent screening for passive hip laxity using a hip distraction view. All the animal procedures undertaken as part of the work described in this abstract were performed in compliance with the regulations of our institutions, and in accordance with the Portuguese and European regulations for animal use and care (European Directive 2010/63/EU and National Decree-Law 113/2013). Due to the retrospective and observational nature of the study, the ethical committee approval and the owner consent were waived.

The radiographs were performed between the years of 2002 and 2013, at the Veterinary Teaching Hospital of University of XXX, with dogs under deep sedation using medetomidine (Domitor®, Orion Corporation, Espoo, Finland) and butorphanol (Torbugesic Injectable ${ }$, Fort Dodge Veterinaria, Girona, Spain) intravenously. The sedation was reversed with atipamezole hydrochloride (Antisedan $®$, Orion Corporation, Espoo, Finland) intramuscularly. 
All images were acquired by the same certified PennHIP examiner (MG) with dogs in dorsal decumbency on the X-ray table and the distractor (PennHIP distractor®, Synbiotics Corporation, San Diego, USA) placed between hind limbs to promote passive hip laxity. Recorded data included breed, age at time of the radiography, sex and bodyweight. The inclusion criteria were hip distraction views, with official hip laxity report at the PennHIP Analysis Center (PAC).

A specific dedicated semiautomatic computer software was used to measure the hip laxity by calculating the distraction index. This software requires that hip evaluator places three points on the border of the femoral head and two points in the acetabular border. Then, the computer software was programmed to delimitate the femoral head and the acetabulum, to determine its diameters and centers, and the distance between the centers (Figure 1). All this information was exported to a database and the distraction index was calculated. The distraction index was calculated as previously described (Smith et al., 1990), the distance between the acetabular and femoral head centers was divided by the radius of the femoral head.

The study was performed in a double-blind fashion by the investigators. The anonymized studies were provided to two blinded evaluators, experienced small animal radiologists, one previously trained (TEv) for hip laxity measurement and the other with experience in radiographic evaluation but without any specific training (NTEv).

The two blinded investigators imported the images to the dedicated software. Two independent sessions (S1 and S2) were performed by each investigator. Then results of each evaluator sessions were compared between each other to evaluate the repeatability, and posteriorly with the official PAC reports to test the reproducibility of measurements (Lee et al., 1989).

Statistical analysis was performed using the computer software SPSS (SPSS Statistics for Windows Version 23.0: IBM Corp., Armonk, NY, USA). The data analysis was performed on joints individually. The paired T-test and intra-class correlation coefficient (ICC) were used in order to evaluate the intra-observer independent measurement sessions agreement (repeatability) and inter-observer agreement with the official PAC reports (reproducibility). The $\mathrm{P}<0.05$ was considered to be statistically significant.
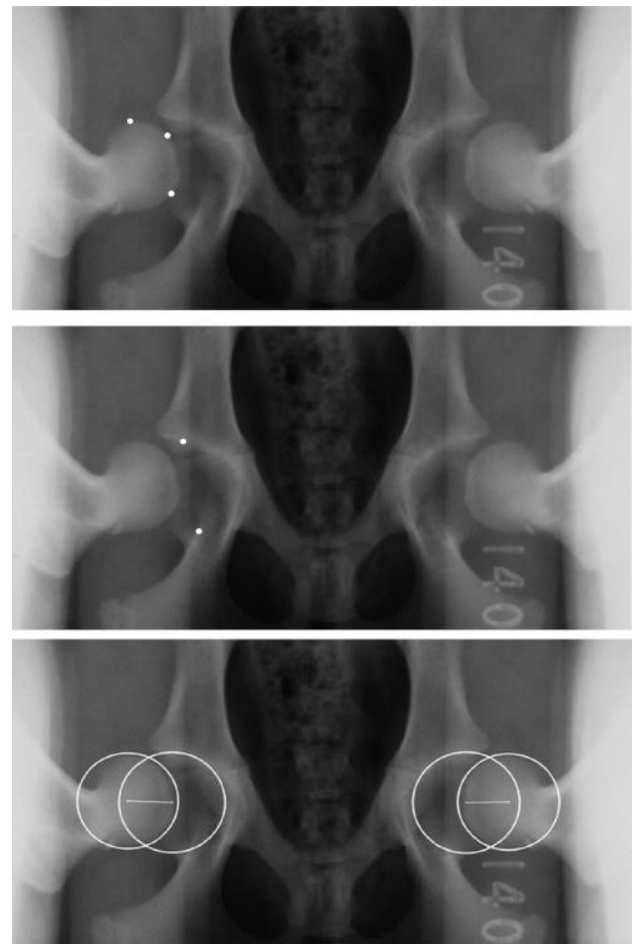

Figure 1. Assessment of the anatomical parameters on the dog's hip joint using the dedicated software. (a) three points are marked by the evaluator on the border of the femoral head. (b) two points are marked in the acetabular border. (c) the computer software delimitates both the femoral head and the acetabulum.

\section{RESULTS}

The dog's age ranged from 4 to 36 months, mean $5.5 \pm 4.9$ months and bodyweight ranged from 8 to $45 \mathrm{~kg}$, mean $21.6 \pm 6.4 \mathrm{~kg}$. The mean distraction index \pm standard deviation in PAC reports was $0.44 \pm 0.15$, TEv_S1 $0.44 \pm 0.16$ and TEv_S2 $0.44 \pm 0.16$ (Table 1 ). The paired T-test was not significant $(\mathrm{P}>0.05)$ for all comparisons except between PAC results and NTEv measurement sessions. In Figure 2 are represented the differences between PAC official distraction index reports and TEv_S1 using the semiautomatic software. 
Table 1. The mean \pm standard deviation of the measurements obtained in the two sessions (S1 and S2) by trained (TEv) and non-trained (NTEv) evaluators and in the PennHIP Analysis Center reports

\begin{tabular}{cccc} 
Evaluator & $\begin{array}{c}\text { Distraction } \\
\text { index }\end{array}$ & $\begin{array}{c}\text { Femoral head } \\
\text { diameter }(\mathrm{mm})\end{array}$ & $\begin{array}{c}\text { Distance between the centres of femoral } \\
\text { head and acetabulum }(\mathrm{mm})\end{array}$ \\
\hline TEv_S1 & $0.44 \pm 0.16$ & $24.8 \pm 2.5$ & $5.5 \pm 2.1$ \\
TEv_S2 & $0.44 \pm 0.16$ & $24.8 \pm 2.5$ & $5.5 \pm 2.1$ \\
NTEv_S1 & $0.47 \pm 0.17$ & $24.4 \pm 2.4$ & $5.8 \pm 2.1$ \\
NTEv_S2 & $0.47 \pm 0.17$ & $24.4 \pm 2.4$ & $5.8 \pm 2.1$ \\
PennHIP Analysis & $0.44 \pm 0.15$ & - & - \\
Center & 229 & 229 & 229 \\
Degrees of freedom & & &
\end{tabular}

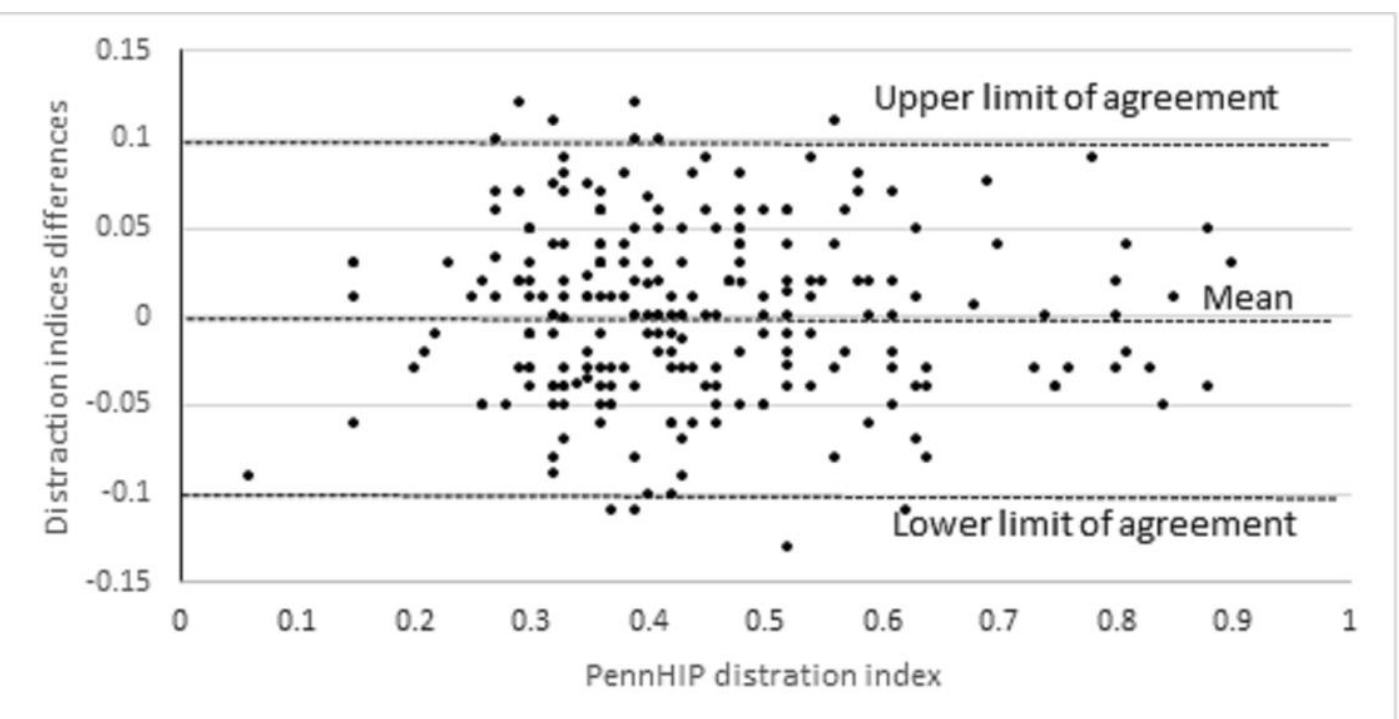

Figure 2. Differences between PennHIP official distraction index reports and the first session of measurements by the trained evaluator using the semiautomatic software. The horizontal lines represent the mean of the differences (0.003) and the upper and lower 95\% limits of agreement, approximately 0.1 and 0.1 , respectively.

The mean femoral head diameter in TEv_S1 and TEv_S2 was $24.8 \pm 2.5 \mathrm{~mm}$ and in the NTEv_S1 and NTEv_S2 was $24.4 \pm 2.4 \mathrm{~mm}$. The mean femoral head and acetabular centers distance in TEv_S1 and TEv_S2 was $5.5 \pm 2.1 \mathrm{~mm}$ and in the NTEv_S1 and NTEv_S2 was $5.8 \pm 2.1 \mathrm{~mm}$. The ICC for distraction index results between TEv_1 and TEv_S2 was 0.96 (95\% confidence interval [CI], 0.95 to 0.97$)$, PAC results and TEv_S1 was 0.95 (95\% CI, 0.94 to 0.96), NTEv_S1 and NTEv_S2 was 0.94 (95\% CI, 0.92 to 0.95$)$, and PAC results and NTEv_S1 0.90 (95\% CI, 0.88 to 0.93).

\section{DISCUSSION}

We have described a novel automated technique for measuring hip joint laxity, which is usually assessed for screen hip dysplasia in order to select dogs for breeding and with treatment purposes. We evaluated the intra-observer ICCs (repeatability) and inter-observer ICCs (reproducibility) of the distraction index, comparing to existing official PAC records. The TEv had the highest repeatability and reproducibility of all parameters assessed (ICC > 0.95), indicating excellent agreement for intra-observer and inter-observer measurements. The results suggest that this computer software, when used by trained evaluators, is accurate for measuring the hip laxity, as the measurements obtained shown statistically adequate repeatability and reproducibility of the PAC official results (Table 1) (Lee et al., 1989, Ginja et al., 2006). The homogeneity for ICC of the TEv suggests the presence of both efficiency of the 
algorithm for the analysis of the morphometric parameters and precision displayed by the trained observer in the selection of points, also patent in Figure 2. However, it requires some previous evaluator training mainly to learn the identification of anatomic femoral and acetabular landmarks. The repeatability obtained by the non-trained evaluator is a good indicator, and a slight training could be enough to improve the final results (Table $1)$.

The use of an automated protocol allows consistent measurements, decreasing manual operations and operator-related biases, being a less timeconsuming procedure. Additionally, as this program exports more technical information to the database sheet, it facilitates the potential training of new users, because it allows to detect if the main failures in the measurements are due to errors in the delimitation of the femoral head or in its distance to acetabulum, the two variables are used for the calculation of the distraction index (Figure $1)$.

Similar distraction measurement results were described in a previous report, using the imaging analysis non-specific software OSIRIS version 3.1 (Ginja et al., 2006). However, the simplicity of the process for hip laxity evaluation with the methodology proposed, performed only by the placement of five points, makes it easier and allows the evaluator to save time. Thus, we think that it would be possible to make the distraction index measurement process more affordable.

The evaluation of this specific parameter of the hip joint is crucial for the knowledge of the conformation present in breed populations, especially those susceptible to dysplasia, such as the large and giant breeds. The hip laxity reveals as the main risk factor for the development of secondary osteoarthritis in dogs with canine hip dysplasia (Smith et al., 1993, Andronescu et al., 2015, Gaspar et al., 2016). So, passive hip laxity is nowadays important for hip dysplasia management and breeding purposes (Smith et al., 1995, Vezzoni et al., 2005). Animals with lower hip laxity are considered better, since they will transmit to the offspring few genes that favor the development of canine hip dysplasia and do not need preventive disease treatment (Fluckiger et al., 1999, Vezzoni et al., 2005, Ginja et al., 2008b). Thereby, the distraction index is currently recommended to select the dog breeding stock, taking into account the desired genetic improvement for hip dysplasia or to decide preventive treatment options (Todhunter et al., 2003, Vezzoni et al., 2005, Ginja et al., 2015).

The distraction index can be calculated at early ages, by measuring the relative displacement of the geometric centre of the femoral head to the center of the acetabulum in distraction hip views, when lateral stress is applied to the femoral head by the examiner using a specific distractor (Smith et al., 1990, Vezzoni et al., 2005, Ginja et al., 2008a). However, centralizing the information and charging fees not always accessible for the measurement of hip laxity in dogs by the only certifying entity, may justify the reduced clinical use of hip laxity in countries with lower economic resources.

Based on previous reports, dogs judged as phenotypically normal by the conventional radiographic degenerative joint disease signs, harbored clinically important passive hip joint laxity determined in distraction view (Ginja et al., 2010). Previous research suggested that hip dysplasia scoring based on hip ventrodorsal view underestimated susceptibility to osteoarthritis in dogs, which may impede progress in reducing or eliminating the disease through breeding (Powers et al., 2010). It seems like the Norberg angle measured on a ventrodorsal extended hip radiographic view was not adequate to measure hip laxity, as the extension of the hind legs tightens the joint capsule, the ligament of the femoral head and associated muscles fostering joint congruence (Smith et al., 1990), and was not an accurate predictor of normal hip conformation at the common cut-off of Norberg angle $\geq 105^{\circ}$ (Gaspar $e t$ al., 2016).

On the other hand, the age and the disease development have direct interference in femoral neck and acetabular morphometric parameters and may difficult the selection of better animals for breeding (Martins et al., 2012). The hip laxity is an animal variable with higher heritability than degenerative joint disease, and if used as a selection criterion, a bigger hip improvement quality per generation is expected (Ginja et al., 2008b). So, a greater dissemination and use of hip laxity for monitoring dog breeds can be very helpful in terms of hip dysplasia control and preventive management, as well as for morphological studies in different breeds. 
It can be concluded that the dedicated semiautomatic computer software is reliable for measuring the distraction index when used by trained observers, as it reproduces the PAC reports. Little training seems enough to perform accurate measurements. The simplicity of the process, based only on the placement of five points on each joint is an advantage, as it is a less time-consuming procedure, making the hip laxity reading procedure more affordable. The additional morphological information exported to the database allows the precise detection of errors in measurements, important during the training of future observers. In the future, the method may be useful for a more detailed morphological study of the hip joint in canine populations.

\section{ACKNOWLEDGEMENTS}

This work was supported by National Funds by FCT - Portuguese Foundation for Science and Technology, under the projects UIDB/04033/2020 and Scientific Employment Stimulus - Institutional Call - CEECINST/00127/2018 UTAD.

\section{REFERENCES}

ANDERSON, A. Treatment of hip dysplasia. $J$. Small Anim. Pract., v.52, p.182-189, 2011.

ANDRONESCU, A.; KELLY, L.; KEARNEY, M.T. et al. Associations between early radiographic and computed tomographic measures and canine hip joint osteoarthritis and maturity. Am. J. Vet. Res., v.76, p.19-27, 2015.

BAUSMAN, J.A.; WENDELBURG, K.L. Evaluation of the effect of pelvic tilt in the coronal plane on the Norberg angle measured in ventrodorsal radiographic views of a canine hip joint bone model. Associations between early radiographic and computed tomographic measures and canine hip joint osteoarthritis. Am. J. Vet. Res., v.71, p.1348-1353, 2010.

BUTLER, J.R.; GAMBINO, J. Canine hip dysplasia: diagnostic imaging. Vet. Clin. N. Am. Small Anim. Pract., v.47, p.777-793, 2017.

FARESE, J.P.; LUST, G.; WILLIAMS, A.J. et al. Comparison of measurements of dorsolateral subluxation of the femoral head and maximal passive laxity for evaluation of the coxofemoral joint in dogs. Am. J. Vet. Res., v.60, p.1571-1576, 1999.
FLUCKIGER, M.A.; FRIEDRICH， G.A.; BINDER, H. A radiographic stress technique for evaluation of coxofemoral joint laxity in dogs. Vet. Surg., v.28, p.1-9, 1999.

GASPAR, A.R.; HAYES, G.; GINJA, C. et al. The Norberg angle is not an accurate predictor of canine hip conformation based on the distraction index and the dorsolateral subluxation score. Prev. Vet. Med., v.135, p.47-52. 2016.

GENEVOIS, J.P.; REMY, D.; VIGUIER, E. et al. Prevalence of hip dysplasia according to official radiographic screening, among 31 breeds of dogs in France. Vet. Comp. Orthop. Traumatol., v.21, p. 21-24, 2008.

GINJA, M.; GASPAR, A.R.; GINJA, C. Emerging insight into the genetic basis of canine hip dysplasia. Vet. Med., v.6, p.193-202, 2015.

GINJA, M.M.; FERREIRA, A.J.; JESUS, S.S. et al. Comparison of clinical, radiographic, computed tomographic and magnetic resonance imaging methods for early prediction of canine hip dysplasia. Vet. Rad. Ultrasound, v.50, p.135-143, 2009b.

GINJA, M.M.; SILVESTRE, A.M.; FERREIRA, A.J. et al. Passive hip laxity in Estrela mountain dog - distraction index, heritability and breeding values. Acta Vet. Hung., v.56, p.303-312, 2008 b.

GINJA, M.M.; SILVESTRE, A.M.; FERREIRA, A.J. et al. Repeatability and reproducibility of distraction indices in examinations of the hip joints in dogs. Acta Vet. Hung., v.54, p.387-392, 2006.

GINJA, M.M.; SILVESTRE, A.M; COLAÇO, J. et al. Hip dysplasia in Estrela mountain dogs: prevalence and genetic trends 1991-2005. Vet. J., v.82, p.275-282, 2009a.

GINJA, M.M.D.; GONZALO-ORDEN, J.M.; MELO-PINTO, P. et al. Early hip laxity examination in predicting moderate and severe hip dysplasia in Estrela mountain dog. J. Small Anim. Pract., v.49, p.641-646, 2008a.

GINJA, M.M.D.; SILVESTRE, A.M.; GONZALO-ORDEN, J.M.; FERREIRA, A.J. Diagnosis, genetic control and preventive management of canine hip dysplasia: a review. Vet. J., v.184, p.269-276, 2010.

LEE, J.; KOH, D.; ONG, C.N. Statistical evaluations of agreement between two methods for measuring a quantitative variable. Comput. Biol. Med., v.19, p.61-70, 1989. 
MARTINS, J.; COLAÇO, B.; ALVESPIMENTA, S. et al. Effect of the dog positioning on x-ray table on hip dysplasia parameter evaluation. Vet. Comp. Orthop. Traumatol., v.32, p.376-382, 2019.

MARTINS, J.; COLAÇO, B.J.; ALVESPIMENTA, S. et al. Effects of pelvis rotation on projected radiographic position of femoral head in relationship to acetabulum. Vet. Med., v.62, p.377385,2017 a.

MARTINS, J.; COLAÇO, B.J.; ALVESPIMENTA, S. et al. Femoral rotation and relationship between the femoral head and the acetabulum. Vet. Med., v.62, p.589-595, 2017 b.

MARTINS, J.; FERREIRA, A.J.; GINJA, M.M. Morphometric assessment of the hip joint in the Estrela Mountain Dog breed. Vet. Comp. Orthop. Traumatol., v.25, p.202-210, 2012.

POWERS, M.Y.; KARBE, G.T.; GREGOR, T.P. et al. Evaluation of the relationship between 'Orthopedic Foundation for Animals' hip joint scores and PennHIP distraction index valuesin dogs. J. Am. Vet. Med. Assoc., v.237, 532-541, 2010.

SCHNELLE, G.B. Some new diseases in dog. Am. Kennel Gazz., v.52, p.25-26, 1935.

SMITH, G.K.; BIERY, D.N.; GREGOR, T.P. New concepts of coxofemoral joint stability and the development of a clinical stress-radiographic method for quantitating hip joint laxity in the dog. J. Am. Vet. Med. Assoc., v.196, p.59-70, 1990.

SMITH, G.K.; GREGOR, T.P.; RHODES, W.H. et al. Coxofemoral joint laxity from distraction radiography and its contemporaneous and prospective correlation with laxity subjective score, and evidence of degenerative joint disease from conventional hip-extended radiography in dogs. Am. J. Vet. Res., v.54, p.1021-1042, 1993.
SMITH, G.K.; POPOVITCH, C.A.; GREGOR, T.P. et al. Evaluation of risk factors for degenerative joint disease associated with hip dysplasia in dogs. J. Am. Vet. Med. Assoc., v.206, p.642-647, 1995.

TARONI, M.; GENEVOIS, J.P.; VIGUIER, E. et al. Evolution of radiographic parameters of canine passive hip laxity at 4, 6 and 12 months: a study of 306 dogs. Vet. Comp. Orthop. Traumatol., v.31, p.321-326, 2018.

TODHUNTER, R.J.; WILFAND, A.; WILLIAMS, A.J. et al. Evaluation of multiple radiographic predictors of cartilage lesions in the hip joints of eight-month-old dogs. Am. J. Vet. Res., v.64, p.1472-1478, 2003.

TÔRRES, R.C.S.; ARAÚJO, R.B.; REZENDE, C.M.F. Distrator articular no diagnóstico radiográfico precoce da displasia coxofemoral em cães. Arq. Bras. Med. Vet. Zootec., v.57, p.27-34, 2005.

VERHOEVEN, G.; COOPMAN, F.; DUCHATEAU, L. et al. Interobserver agreement in the diagnosis of canine hip dysplasia using the standard ventrodorsal hip extended radiographic method. J. Small Anim. Pract., v.48, p.387-393, 2007.

VEZZONI, A.; DRAVELLI, G.; CORBARI, A. et $a l$. The early diagnosis of canine hip dysplasia. Eur. J. Comp. Anim. Pract., v.15, p.173-184, 2005.

WILSON, B.; NICHOLAS, F.W.; THOMSON, P.C. Selection against canine hip dysplasia: success or failure? Vet. J., v.89, p.160-168, 2011.

ZHANG, Z.; ZHU, L.; SANDLER, J. et al. Estimation of heritabilities, genetic correlations, and breeding values of four traits that collectively define hip dysplasia in dogs. Am. J. Vet. Res., v.70, p.483-492, 2009. 